\title{
Analysis of Heat Transfer in the VVER-1200 Reactor's Heat Channel
}

\author{
Dinh Van Thin 1,*, Bui Van Loat ${ }^{2}$, Bui Thi Hong ${ }^{2}$ \\ ${ }^{I}$ Department of Nuclear Power, Electric Power University \\ ${ }^{2}$ Department of Nuclear Physics, VNU University of Science, 334 Nguyen Trai, Hanoi, Vietnam
}

Received 08 June 2017

Revised 15 August 2017; Accepted 15 September 2017

\begin{abstract}
In early 2015, the Government of Vietname has decided to choose VVER-1200 Russian-made technology for building at the Nuclear Power Plant in Ninh Thuan 1, this is the advanced reactor generation III + and the only one has been completed for the first time in the world in August 2016. Vietnam is facing a major challenge, which is how to ensure the acquired technology transfer process, then the safe operation of thisunit.

This article analyzes some of the heat changes occur in reactor when there are changes of the heatflux. This is an issue directly related to the workof predictingincidents and give ways to fix the problem when the plant is in conditions such as startup, normal and abnormaloperations.

For analysis, the authors used CFD methods, this is a very modern method and have high reliability. The results received have fit well when compared with the safety analysis report of Rosatom published.
\end{abstract}

Keywords: Reactor thermalhydraulics, VVER-1200, CFD.

\section{Introduction}

The core of VVER-1200 reactor is designed with due consideration of the TOR for the reactor plant of NPP-2006, which stipulates considerable increase of the parameters determining the performance of an nuclear power plant- performance factor and availability factor of the Unit as compared to the commercial VVER-1000 reactor. In particular, it is necessary to increase the thermal power to $3200 \mathrm{MW}$, to provide for 12 months long operation between refuelling taking into account planned outage for refuelling. The basic fuel cycle is considered to have the cycle length about 340 EFFD, maximum fuel burnup in fuel assemblies is expected to be up to $70 \mathrm{MW} \cdot$ day $/ \mathrm{kgU}[4]$.

Many of the technical and design solutions, used in the design of the core VVER-1200. The main solutions providing for increasing the amount of fuel in the core are asfollows:

Elongation of the fuelcolumn.

\footnotetext{
*Corresponding author. Tel.: 84-973062777.

Email: thindv@epu.edu.vn

https//doi.org/ 10.25073/2588-1124/vnumap.4220
} 
Increasing the external diameter of the fuelpellet.

Reducing the centrelinehole.

Table 1. Main technical characteristics of the VVER-1200 (B-392M)[4]

\begin{tabular}{|c|c|c|c|}
\hline Characteristics & Value & Characteristics & Value \\
\hline Number of fuel assemblies in the core. & 163 & $\begin{array}{l}\text { Spacing between fuel rods, } \\
\mathrm{mm} .\end{array}$ & 12.75 \\
\hline Thermal reactor power, MW. & 3200 & Fuel cladding material. & E110 \\
\hline $\begin{array}{l}\text { Absolute coolant pressure at the reactor } \\
\text { outlet, MPa. }\end{array}$ & 16,2 & $\begin{array}{l}\text { External diameter of fuel } \\
\text { cladding, mm. }\end{array}$ & 9.1 \\
\hline Coolant temperature at reactor inlet, ${ }^{\circ} \mathrm{C}$. & $298.2 \pm 4$ & $\begin{array}{l}\text { Internal diameter of fuel } \\
\text { cladding, mm. }\end{array}$ & 7.73 \\
\hline Coolant temperature at reactor outlet, ${ }^{\circ} \mathrm{C}$. & $328.9 \pm 5$ & $\begin{array}{l}\text { External diameter of fuel } \\
\text { pellet, } \mathrm{mm} .\end{array}$ & 7.6 \\
\hline Core flow at the inlet, $\mathrm{m}^{3} / \mathrm{h}$. & $83420 \pm 2900$ & $\begin{array}{l}\text { Diameter of centerline hole } \\
\text { in the fuel pellet, } \mathrm{mm} \text {. }\end{array}$ & 1.2 \\
\hline Fuel assembly hight, mm. & 4570 & Height of fuel column, mm. & 3730 \\
\hline Number of fuel rods in a fuel assembly. & 312 & $\mathrm{UO}_{2}$ mass in the fuel rod, $\mathrm{kg}$. & 1.71 \\
\hline
\end{tabular}

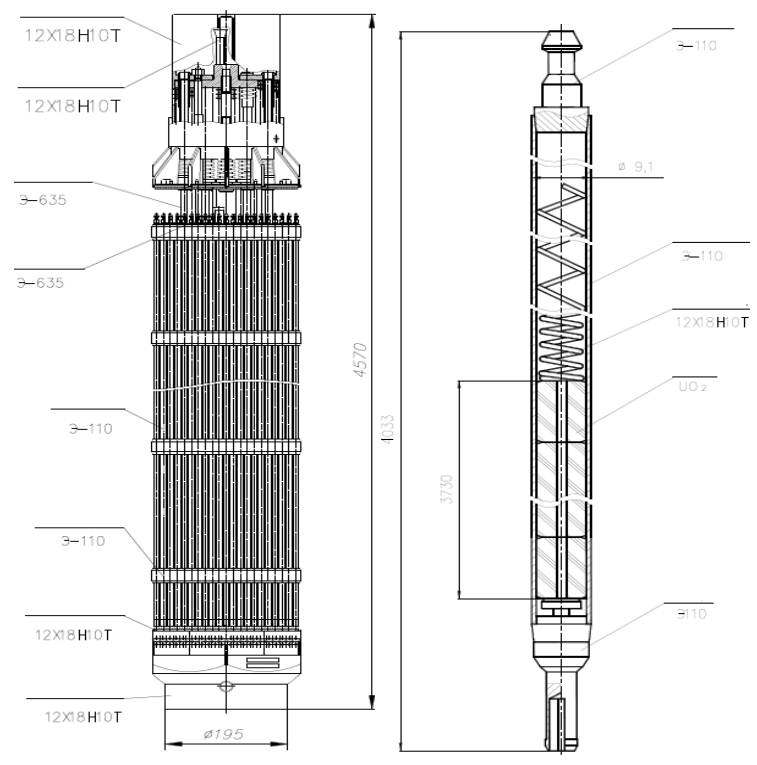

Fig. 1. Fuel assembly and Fuel Rod.

\section{Researching methodology}

Computational fluid dynamics or CFD is the analysis of systems involving fluid flow, heat transfer and associated phenomena such as chemical reactions by means of computer-based simulation. The CFD method uses the meshing tools to separate the large-sized objects into the small pieces then 
applies three conservation equations of physics:Newton's second law; Mass conversation and first law of thermodynamics to solve the problems. The technique is very powerful and spans a wide range of industrial and non-industrial application areas [1,7].

We describe the behavior of the fluid in terms of macroscopic properties, such as velocity, pressure, density and temperature, and their space and time derivatives. We consider such a small element of fluid with sides $\delta x, \delta y$ and $\delta z$. All fluid properties are functions of space and time: $\rho(x, y, z$, $t), p(x, y, z, t), T(x, y, z, t)$ and $u(x, y, z, t)[1,7]$.

We have the temperature of the fuel rod cladding outer surface depends on coolant temperature, heat flux value and heat transfer coefficient from fuel rod surface $[2,4,6]$ :

$$
T_{\text {clad }}(z)=T_{\mathrm{w}}(z)+\frac{q^{\prime \prime}(z)}{\alpha}
$$

Where: Tclad (z)- Temperature of the fuel rod cladding outer surface, ${ }^{\circ} \mathrm{C} ; \mathrm{q}$ '” $(\mathrm{z})-$ Heat flux from the fuel rod surface, $\mathrm{kW} / \mathrm{m}^{2} \cdot{ }^{\circ} \mathrm{C} ; \mathrm{Tw}(\mathrm{z})$ - Coolant temperature, ${ }^{\circ} \mathrm{C} ; \alpha$ - Heat transfer coefficient from the fuel rod surface, $\mathrm{kW} / \mathrm{m}^{2} \cdot{ }^{\circ} \mathrm{C}$.

With the core coolant parameters corresponding to values of normal operating conditions, the heat transfer coefficient under the conditions of forced convection of one-phase subcooled coolant is determined by formulae $[8,10]$ :

$$
\begin{aligned}
& \alpha=\frac{\lambda}{d_{g}} N u \\
& N u=\left\{\begin{array}{l}
3.66 ; \operatorname{Re}<2300 \\
3.66\left(\frac{\operatorname{Re}}{2300}\right)^{1.565+0.272 \ln (\mathrm{Pr})} ; 2300 \leq \operatorname{Re}<10^{4} \\
0.023 \operatorname{Re}^{0.8} \operatorname{Pr}^{0.4} ; \operatorname{Re} \geq 10^{4}
\end{array}\right\}
\end{aligned}
$$

Where: Nu-Nusselt number; Re-Reynolds number; Pr-Prandtl number; $\lambda$-heat conductivity,W/m; $\mathrm{dg}$-Diameter, $\mathrm{m}$.

When coolant water flows from lower part to upper part in fuel assembly, it occurs the pressure drops:

$p_{\text {in }}-p_{\text {out }}=\Delta p_{\text {inertia }}+\Delta p_{\text {acc }}+\Delta p_{\text {gravity }}+\Delta p_{\text {friction }}+\Delta p_{\text {form }}$

with: $\Delta p_{\text {ineria }}=\sum_{n=1}^{N} \frac{l_{n}}{A_{n}} \frac{\dot{d m}}{d t} ; \Delta p_{\text {acc }}=\frac{\dot{m}^{2}}{2 \rho}\left(\frac{1}{A_{N}^{2}}-\frac{1}{A_{1}^{2}}\right)$;

$$
\Delta p_{\text {gravity }}=\rho g\left(z_{N}-z_{1}\right) ; \Delta p_{\text {form }}=K\left(\frac{\rho v_{\text {ref }}^{2}}{2}\right) ; \Delta p_{\text {friction }}=\bar{f} \frac{L}{D}\left(\frac{\rho v_{\text {ref }}^{2}}{2}\right)
$$

Where: $\rho$-Density, kg/m3; g-Accelerator, $\mathrm{m} 2 / \mathrm{s} ; \mathrm{v}-$ Velocity, $\mathrm{m} / \mathrm{s} ; \mathrm{m}$-Mass flow rate,kg/m; $\mathrm{N}$ - number of sections.

\section{Results and discussions}

We consider the changes of some main parameters under the different values of heat flux, the range of heat flux is from $0.3 \times 10^{6} \mathrm{~W} / \mathrm{m}^{2}$ to $1.486 \times 10^{6} \mathrm{~W} / \mathrm{m}^{2}$, which is critical heat flux. Coolant water have velocity is $5.4865 \mathrm{~m} / \mathrm{s}$, temperature is $271.16 \mathrm{~K}$ and pressure is $16.2 \mathrm{MPa}$. The heat coolant 
channel has 4 fuel rods surround and 12 spacer grids inside as shown in Fig. 2. We obtained some results as following below $[2,6,7]$ :

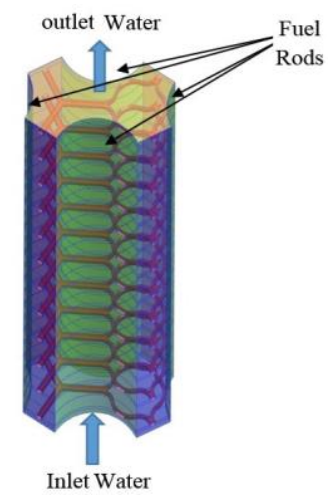

Fig 2. Initial conditions for analysis.

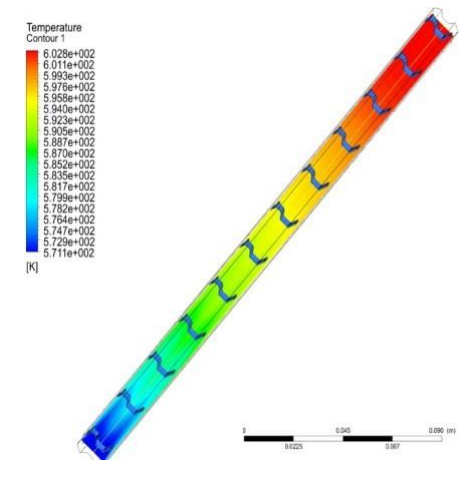

Fig 3. Temperature distribution.

We get data from the line and plane in the middle of the heat coolant channel, the results are provided in the table 2 and fig 3 , fig 4 , fig 5 .

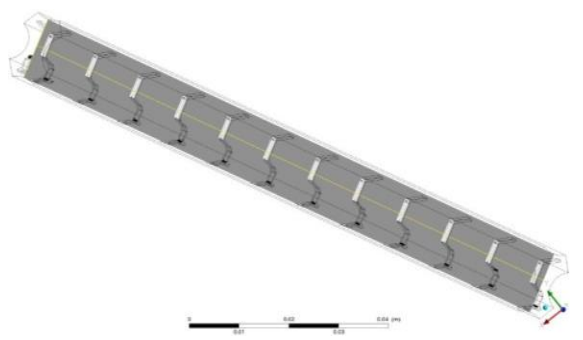

Fig 4. The line and plane in middle of heat coolant channel.

Table 2. The obtained results by CFD analysis.

\begin{tabular}{llllll}
\hline $\begin{array}{l}\text { Heat flux } \\
\left(\mathrm{W} / \mathrm{m}^{2}\right)\end{array}$ & $\mathrm{T}_{\text {in }}(\mathrm{K})$ & $\mathrm{T}_{\text {out }}(\mathrm{K})$ & $\mathrm{T}_{\text {clad } \min (\mathrm{K}) \mathrm{T}_{\text {clad }}}$ \\
averaged $(\mathrm{K})$ & $\begin{array}{l}\mathrm{T}_{\text {clad }} \max \\
(\mathrm{K})\end{array}$ \\
\hline 300000 & 571.16 & 589.08 & 571.18 & 581.81 & 590.75 \\
400000 & 571.16 & 594.70 & 571.19 & 585.21 & 596.84 \\
500000 & 571.16 & 599.94 & 571.20 & 588.50 & 602.51 \\
600000 & 571.16 & 605.08 & 571.22 & 591.71 & 608.00 \\
700000 & 571.16 & 609.90 & 571.23 & 594.81 & 613.09 \\
800000 & 571.16 & 614.37 & 571.24 & 597.78 & 617.73 \\
900000 & 571.16 & 618.45 & 571.25 & 600.62 & 621.84 \\
1000000 & 571.16 & 622.07 & 571.26 & 603.30 & 625.29 \\
1100000 & 571.16 & 625.16 & 571.27 & 605.80 & 628.01 \\
1200000 & 571.16 & 627.55 & 571.28 & 608.10 & 629.33 \\
1300000 & 571.16 & 629.04 & 571.29 & 610.12 & 630.17 \\
1486199 & 571.16 & 630.14 & 571.31 & 613.23 & 630.23 \\
\hline
\end{tabular}




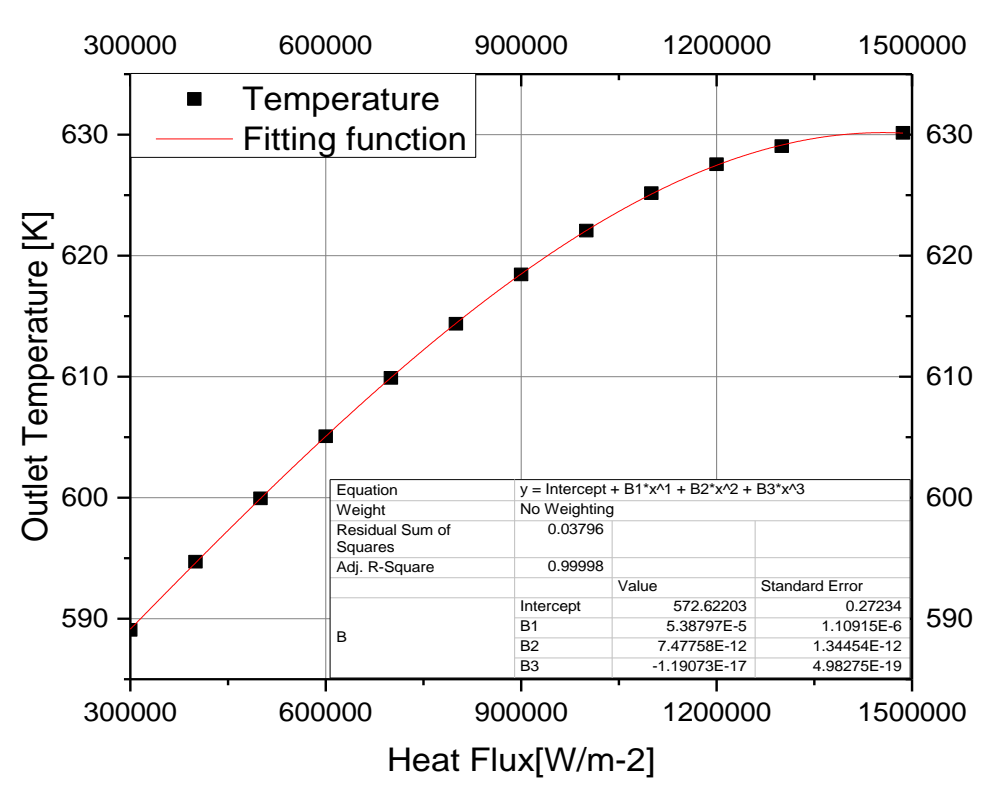

Fig 5. Temperature distribution with the change of heat flux.

From the chart, we get the function related between temperature at outlet plane and heat flux:

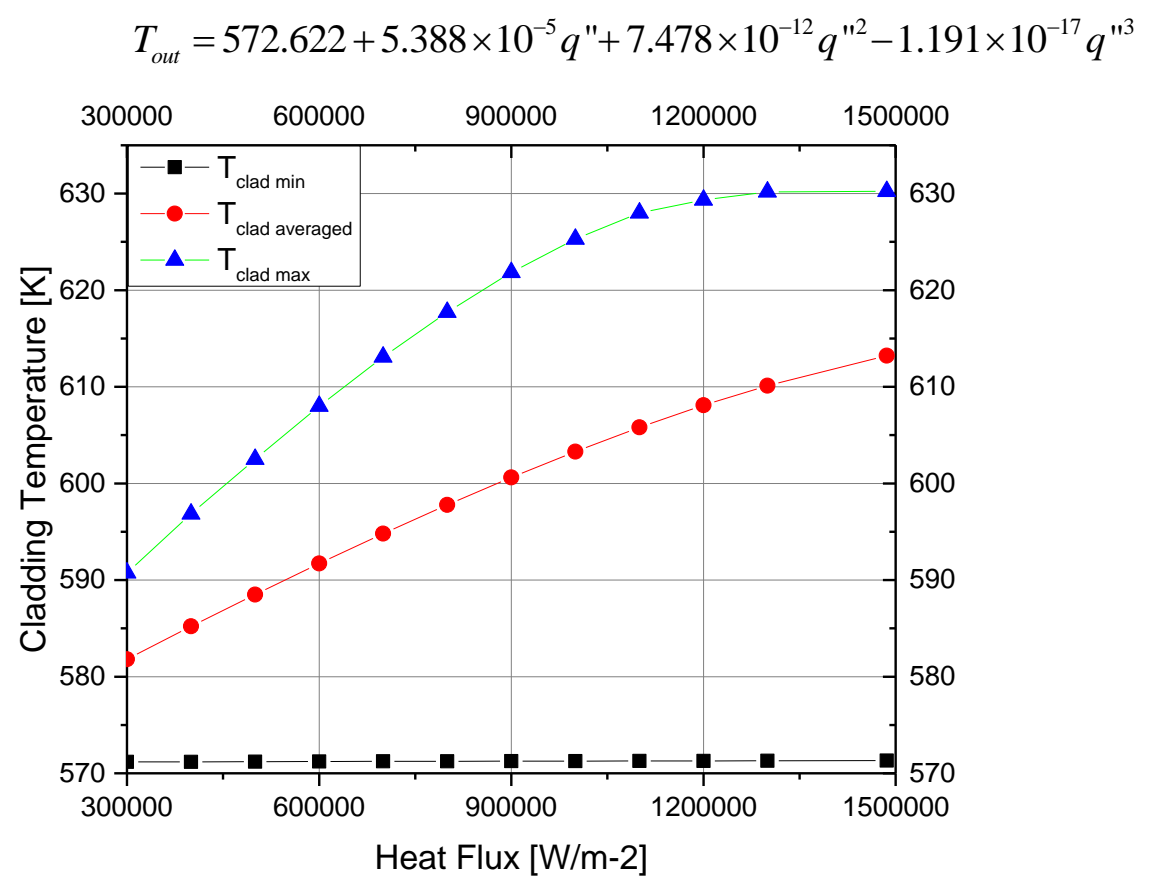

Fig 6a. Cladding temperature changes with heat flux. 


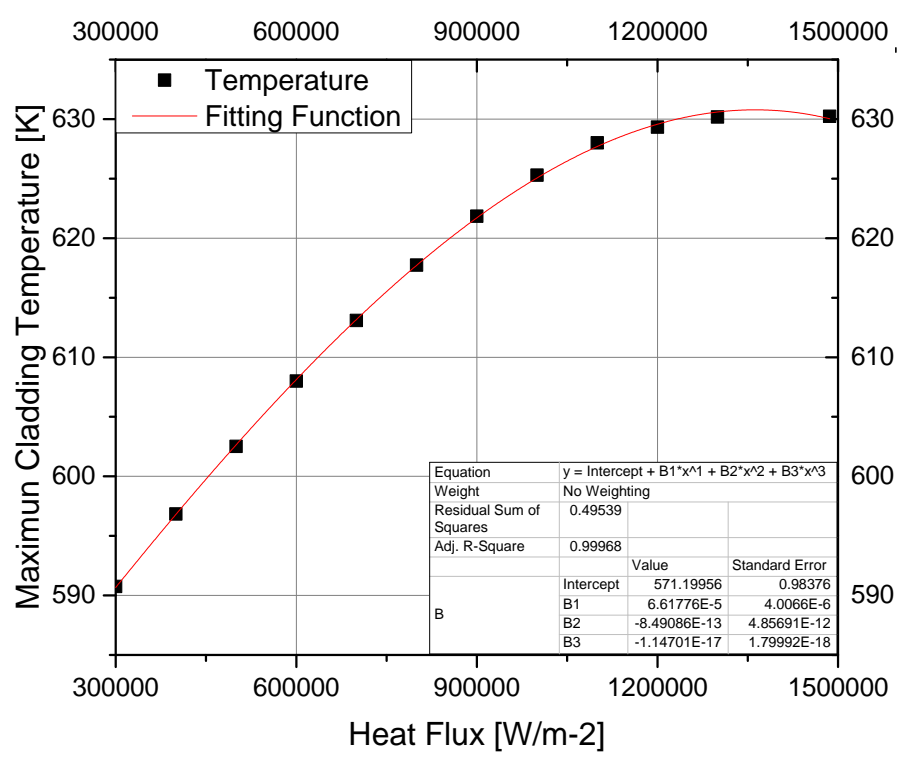

Fig 6b. Cladding temperature changes with heat flux.

The function related between maximum cladding temperature and heat flux:

$$
T_{\text {cladMax }}=571.2+6.618 \times 10^{-5} q^{\prime \prime}-8.491 \times 10^{-13} q^{\prime \prime 2}-1.147 \times 10^{-17} q^{13}
$$

From all results, we can see that CFD method is useful and powerful tomodel and simulate all fluid processes, including fluid-structure multiphysicsinteractions. The results show that if the heat flux change from $0.3 \times 10^{6} \mathrm{~W} / \mathrm{m}^{2}$ to $1.486 \times 10^{6} \mathrm{~W} / \mathrm{m}^{2}$, then all safety criteria are ensure. The maximumtemperature offuel rod cladding is $630.23 \mathrm{~K}$, which is lower than melting temperature value $[6,7]$.

In addition, regarding to the velocity change we can see when the heat flux is $0.5 \times 10^{6} \mathrm{~W} / \mathrm{m}^{2}$ the outlet temperature is $599.94 \mathrm{~K}$ that is suitable in normal operation conditions of VVER-1200.

\section{References}

[1] ANSYS, Inc. ANSYS ICEM CFD Help Manual, 2016.

[2] Reactor plant V-392M. Terms of Reference for Basic Design Development of VVER-1200 Reactor Plant. 392M TZ-001, EDO JSC, 2006.

[3] Fuel Assembly with Rigid Skeleton (TVS-2). Specification of Structural Materials. 464.01 D1. EDB JSC, 2006.

[4] Preliminary Safety Analysis Report, Novovoronezh NPP-2, 2009.

[5] Dinh Van Thin, Analysis of the fluid flow characteristics in subchannels of VVER-1000 reactor's fuel assemblies by CFD method, NUKLEON, Hungary, 2015.

[6] Dinh Van Thin, Three-dimentional analysis of the coolant flow characteristics in the VVER-1000 reactor's fuel assemblies, VINANST11, 2015.

[7] Jiyuan Tu, Guan Heng Yeoh and Chaoqun Liu, Computational Fluid Dynamics, A Practical Approach, Elsevier, 2008. 